\title{
Performance of the L2C civil GPS signal under various ionospheric scintillation effects
}

\author{
H. A. S. Marques ${ }^{1}$ J. F. G. Monico' ${ }^{1}$ H. A. Marques $^{2}$
}

Received: 12 May 2014/ Accepted: 18 June 2015/Published online: 3 July 2015

(C) Springer-Verlag Berlin Heidelberg 2015

\begin{abstract}
As GPS is modernizing, there are currently fourteen satellites transmitting L2C civil code and seven satellites transmitting L5 signal. While the GPS observables are subject to several sources of errors, the ionosphere is one of the largest error sources affecting GPS signals. Small irregularities in the electrons density along the GPS radio signal propagation path cause ionospheric scintillation that is characterized by rapid fluctuations in the signal amplitude and phase. The ionospheric scintillation effects are stronger in equatorial and high-latitude geomagnetic latitude regions and occur mainly due to equatorial anomaly and solar storms. Several researchers have analyzed the L2C signal quality since becoming available in December, 2005. We analyze the performance of L2C using GPS data from stations in the equatorial region of Brazil, which is subject of weak, moderate and strong ionospheric scintillation conditions. The GPS data were collected by Septentrio PolaRxS-PRO receivers as part of the CIGALA/CALIBRA network. The analysis was performed as a function of scintillations indexes S4 and Phi60, lock time (time interval in seconds that the carrier phase is tracked continuously without cycle slips), multipath RMS and position variation of precise point positioning solutions. The analysis shows that L2C code solutions are less affected by multipath effects than that of
\end{abstract}

J. F. G. Monico

jmonico@gmail.com

H. A. S. Marques

heloh2o@gmail.com

1 Sao Paulo State University (UNESP), Roberto Simonsen, 305, Presidente Prudente, SP, Brazil

2 Federal University of Pernambuco (UFPE), Prof. Moraes Rego, 1235, Recife, PE, Brazil
P2 when data are collected under weak ionospheric scintillation effects. In terms of analysis of positions, the kinematic PPP results using L2C instead P2 codes show accuracy improvements up to $33 \%$ in periods of weak or strong ionospheric scintillation. When combining phase and code collected under weak scintillation effects, the results by applying L2C against P2 provide improvement in accuracy up to $59 \%$. However, for data under strong scintillation effects, the use of L2C for PPP with code and phase does not provide improvements in the positioning accuracy.

Keywords Ionospheric scintillation - L2C · GPS modernization · GPS positioning

\section{Introduction}

The GNSS system is composed of GPS, GLONASS, Galileo, BeiDou and augmentation systems such as WAAS and EGNOS. Once fully developed, there are several advantages to the user such as more visible satellites, greater signal power level and more potential observable combinations, resulting in improved positioning accuracy, availability and reliability.

Originally, the GPS satellites transmit signals on L1 and L2 frequencies and more recently also on the third frequency, called L5. Moreover, there is a new civil code on L2 called L2C, which is expected to provide better performance than the encrypted $\mathrm{P}$ code mainly under ionosphere irregularities and other signal disturbances.

The GPS observables are subject to several sources of errors of which the ionosphere is the largest one for singlefrequency users. Other effects such as tropospheric delay and multipath also disturb the quality of the signal. The 
main effect caused by ionosphere is a function of the total electron content (TEC). However, variations in the electron density along the ionospheric layers cause ionospheric scintillation generating variations in amplitude, phase, polarization and angle of the GPS signal. The effects of ionospheric scintillation are stronger in the equatorial and high-latitude geomagnetic regions where the occurrence is usually due to the equatorial anomaly and geomagnetic storms, respectively (Aquino et al. 2009; Maini and Agrawal 2007; Davies 1990; Conker et al. 2002).

Several investigations regarding the $\mathrm{L} 2 \mathrm{C}$ observable have been carried out recently. In al-Fanek et al. (2007), pseudoranges derived from L2C code and carrier phases were assessed by means of carrier to noise (CN0), multipath, phase tracking and other analyses. The application of L2C to estimate ionospheric effects in positioning, aiming to improve the ambiguity solution, was carried out by Wang and O'Keefe (2010). Sreeja et al. (2013) analyzed the correlation between L1C/A and L2C as a function of scintillation indices and receiver lock time among others.

We investigated the $\mathrm{L} 2 \mathrm{C}$ performance taking into account the time series of scintillation indices S4 and Phi60, multipath RMS and receiver lock time, and assess the results for precise point positioning (PPP) by using GPS data under conditions of weak, moderate and strong ionospheric scintillation. The lock time indicates the time interval in seconds that the carrier phase is tracked continuously without occurrence of cycle slips (Hinks et al. 2008). The GPS data and also the scintillation index and lock time were provided by Septentrio PolaRxS-PRO receivers deployed in Brazil within the context of the project CIGALA/CALIBRA (Concept for Ionospheric Scintillation Mitigation for Professional GNSS in Latin America/Countering GNSS high Accuracy applications Limitations due to Ionospheric disturbances in BRAzil) sponsored by the European Commission as part of the FP7GALILEO-2009-GSA and FP7-GALILEO-2011-GSA projects. Although the observables available to the experiments are collected by Septentrio PolaRxS-PRO receivers, the use of other kind of receivers may provide observables with different properties due to the proprietary L2C tracking characteristic. We study the performance of L2C under ionospheric scintillation conditions involving the analysis of S4 and Phi60 indices, lock time, multipath and kinematic PPP using either codes only or code and phase measurements together.

\section{Characteristics of the GPS observable}

The L2C observable has been available since the launch of the first Block IIR-M satellite in 2005, which started the process of GPS modernization. As part of the modernization, the legacy $\mathrm{C} / \mathrm{A}$ and $\mathrm{P}(\mathrm{Y})$ codes on $\mathrm{L} 1$ are supplemented by a new military code L1M, while the L 2 carrier is modulated by the legacy $\mathrm{P}(\mathrm{Y})$ code, a new military $\mathrm{L} 2 \mathrm{M}$ and a new civil L2C code. The L5 carrier available in the Block IIF satellites is modulated by the L5C code (IS-GPS-200G 2012). There are seven Block IIR/IIRM satellites (PRN: 05, 07, 12, 15, 17, 29, 31) and four Block IIF satellites (PRN: 01, 24, 25, 27) transmitting L2C codes as of the second half of 2013. The new GPS signals apply a modulation known as binary offset carrier (BOC), which is a variation of the spread technique called direct-sequence spread spectrum (DSS). The BOC modulation is also being used by the Galileo system (Kaplan and Hegarty 2006; Galileo OS-SIS-ICD 2010). Table 1 summarizes the characteristics of the currently GPS signals.

As can be seen in Table 1, the L2C consists of the civil moderate (CM) and civil long (CL) codes. The former employs a binary sequence that repeats every 10,230 chips while for the CL code the sequence repeats every 767,250 chips. The L2C code is transmitted at frequency $511.5 \mathrm{kHz}$, and the CM and CL codes repeat every $20 \mathrm{~ms}$ and 1.5 s, respectively (Kaplan and Hegarty 2006; IS-GPS200G 2012).

The $\mathrm{L} 2 \mathrm{P}(\mathrm{Y})$ code is generally collected by most civilian receivers applying semicodeless techniques, which can amplify multipath errors and degrade phase track capabilities resulting in frequent loss of lock mainly for low-elevation satellites and under ionospheric scintillation conditions. Therefore, it is expected that $\mathrm{L} 2 \mathrm{C}$ will present a better performance than $\mathrm{L} 2 \mathrm{P}(\mathrm{Y})$ when applied for GPS positioning under such conditions.

\section{Ionospheric scintillation effects}

Ionospheric scintillation in the equatorial regions is related to the equatorial anomaly whose peak electron density can occur near 21-h local time in maximum solar activity periods. Ionospheric bubbles are also formed in this region soon after sunset, and the small irregularities in such bubbles become a source of intense ionospheric scintillation effects (Skone et al. 2001).

The ionospheric scintillation can be quantified by the amplitude scintillation index $\mathrm{S} 4$ and the scintillation phase standard deviation $\sigma_{\phi}$. The $S 4$ index can be computed from satellite signal power or signal intensity (SI) tracked in the receiver and can be interpreted as normalized standard deviation around the intensity average (Van Dierendonck 2001):

$S 4=\sqrt{\frac{E\left\{\mathrm{SI}^{2}\right\}-E\{\mathrm{SI}\}^{2}}{E\{\mathrm{SI}\}^{2}}}$ 
Table 1 Summary of the GPS signals characteristics

\begin{tabular}{llll}
\hline Signal & Frequency $(\mathrm{MHz})$ & Modulation type & Data type \\
\hline L1C/A & 1575.42 & BPSK & Civil \\
L1C & 1575.42 & BOC & Civil \\
L1P(Y) & 1575.42 & BPSK & Military \\
L1M & 1575.42 & BOC & Military \\
L2C $($ CM and CL) & 1227.60 & BPSK & Civil \\
L2P(Y) & 1227.60 & BPSK & Military \\
L2M & 1227.60 & BOC & Military \\
L5C (I5 and Q5) & 1176.45 & BPSK & Civil \\
\hline
\end{tabular}

Source: IS-GPS-200G

Table 2 Ionospheric scintillation levels

\begin{tabular}{lll}
\hline Strong scintillation & S4 $>1.0$ & Phi60 $>0.8$ \\
Moderate scintillation & $0.5 \leq \mathrm{S} 4 \leq 1.0$ & $0.4 \leq$ Phi60 $\leq 0.8$ \\
Weak scintillation & S4 $<0.5$ & Phi60 $<0.4$ \\
\hline
\end{tabular}

where $E\{\cdot\}$ is the mathematical expectation (average) over some interval, say $60 \mathrm{~s}$ for a sample rate of $50 \mathrm{~Hz}$.

The phase standard deviation $\sigma_{\phi}$ (radians) is calculated by using the $50-\mathrm{Hz}$ detrended phase measurements, which are obtained through the high-pass Butterworth filter. The $\sigma_{\phi}$ values are computed at the specific intervals $(1,3,10$, 30 and $60 \mathrm{~s}$ ), and an average provides a $\sigma_{\phi}$ value for every minute, which is labeled Phi60 (Van Dierendonck 2001). Based on Phi60 or S4 indices, the ionospheric scintillation can be classified as weak, moderate or strong as can be seen in Table 2 (Tiwari et al. 2011).

The CIGALA/CALIBRA network is equipped with ionospheric scintillation monitor receivers (ISMRs) that are capable of collecting GNSS data at a sample rate of $50 \mathrm{~Hz}$ and generating hourly files containing such quantities as scintillation indices S4 and Phi60, lock time, satellite elevation angles and TEC. These data are essential for accomplishing the experiments discussed in the next section.

\section{Experiments}

We analyzed the S4 index, Phi60, lock time and multipath and carried out GPS PPP using the L2C observable. The experiments took advantage of the CIGALA/CALIBRA network in Brazil (Fig. 1), which covers the equatorial anomaly region. The data sets collected by Septentrio PolaRxS-PRO receivers were chosen taking into account the ionospheric scintillation conditions and the largest number of satellites tracking L2C data which ranged from 5 to 7 satellites. In all experiments, only data from satellites providing L2C were used. Data from stations PALM,

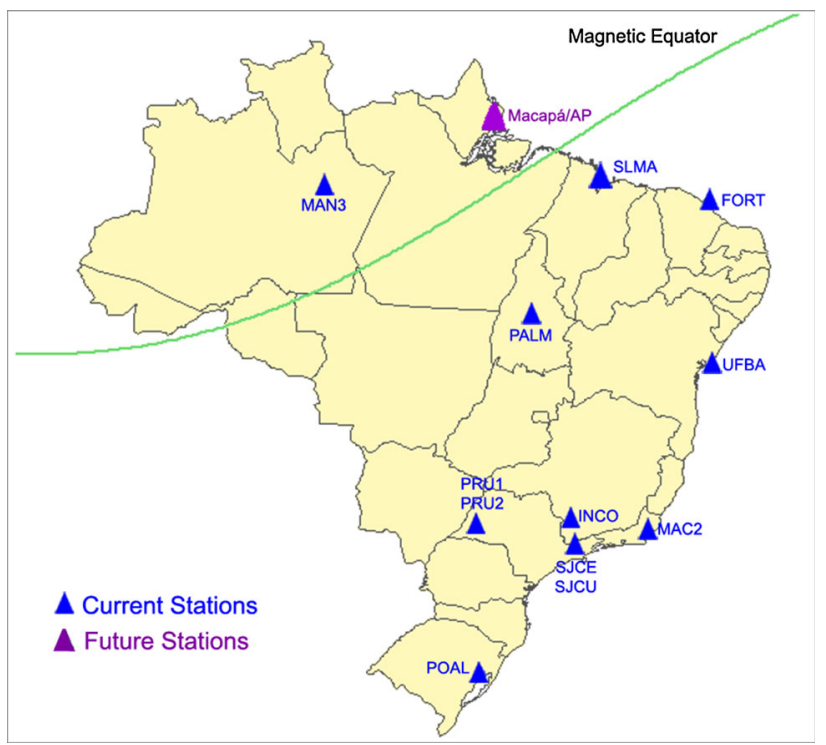

Fig. 1 Stations used in the experiments. Source http://is-cigalacalibra.fct.unesp.br/is/stations/fixed.php

PRU1, SJCU and MAC2 were selected for August 29 (DOY 241), 2013, and November 25 (DOY 329), 2013.

For GPS positioning, the data were initially processed using only pseudoranges and then combined code and carrier phase observations. In both cases, the ionospherefree linear combination was utilized. The S4, Phi60, lock time and multipath analysis will be shown in the next section followed by the PPP results and analysis.

\section{Analysis of L2C observable under ionosphere scintillation effects}

The ionospheric indexes analysis for stations PALM, PRU1, SJCU and MAC2 on DOY 241 and 329 of 2013 is presented. Figure 2 shows the S4 and Phi60 values for L2C code for all selected stations. The mask angle is $10^{\circ}$ for all satellites. This angle was chosen to be in agreement with that used in the PPP data processing. 


\section{DOY 241}

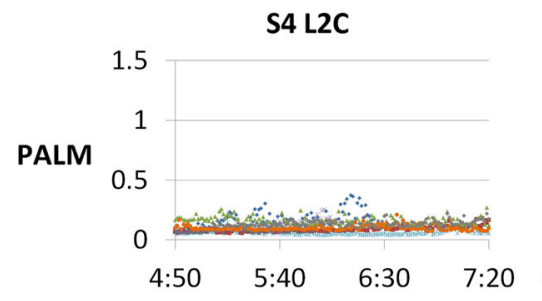

PHI60 L2C
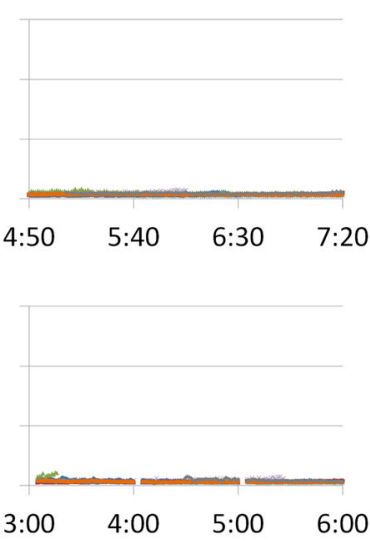

DOY 329
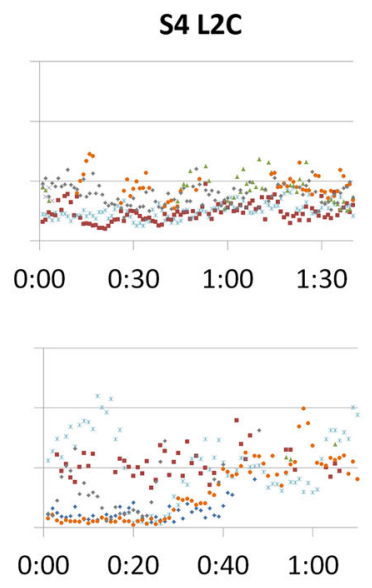
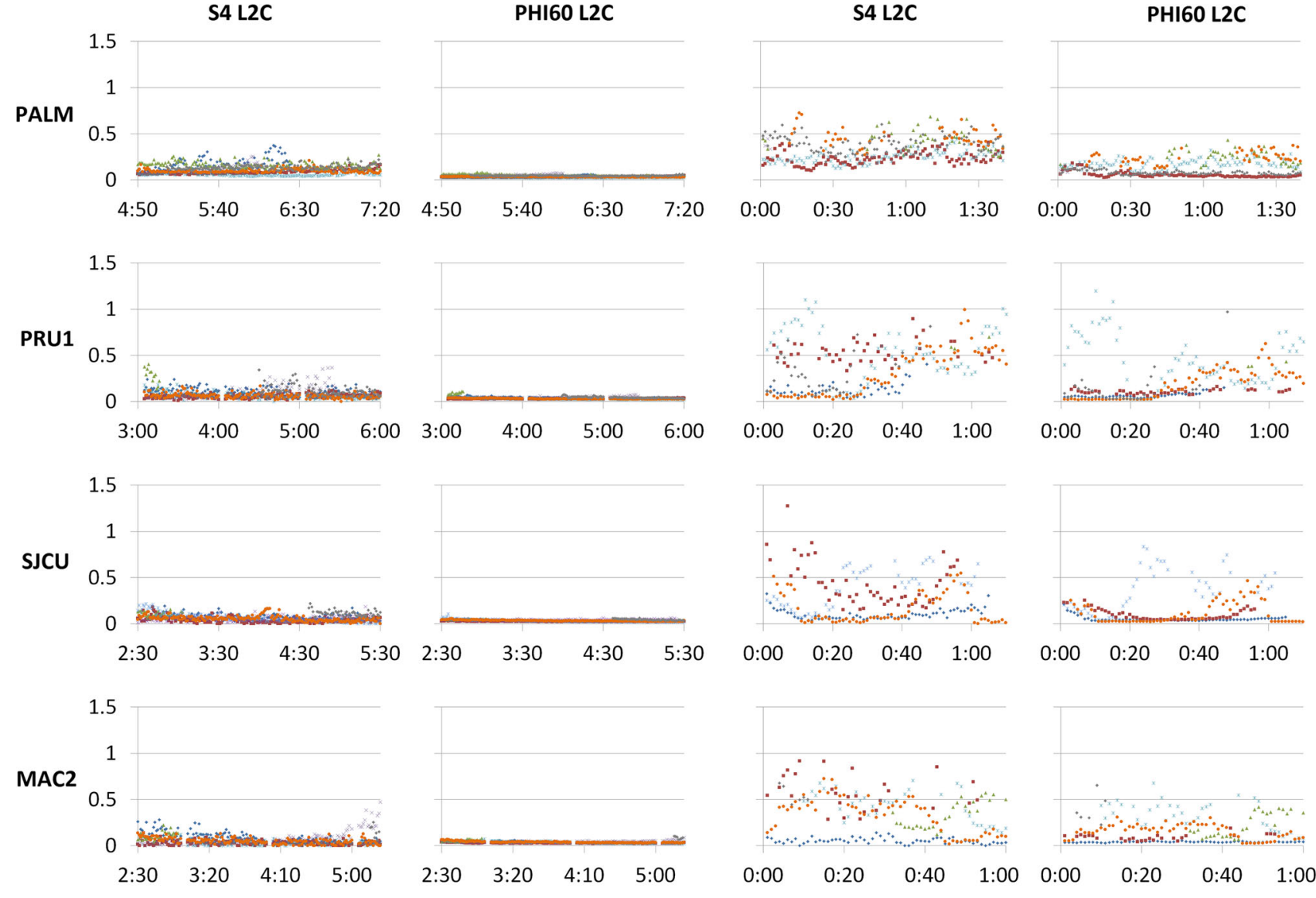

Fig. 2 Scintillation indices S4 and Phi60 for L2C. Horizontal axis is UTC

Analyzing the indices for the DOY 241 in Fig. 2, it is seen that the $\mathrm{S} 4$ and Phi60 values are smaller than 0.5 and 0.4 , respectively, for all stations, which means that the GPS observables were probably collected under conditions of weak ionospheric scintillation (Table 2). For DOY 329, the S4 values are generally between 0.5 and 1.0 and Phi60 is between 0.4 and 0.8 for stations PALM, SJCU and MAC2, which indicates conditions of moderate ionospheric scintillation. However, for PRU1 at DOY 329, the S4 and Phi60 reached values greater than 1.0 and 0.8 , respectively, indicating that the GPS data were observed under conditions of strong ionospheric scintillation.

Figure 3 shows the lock times for L1C/A and L2C at each station for both days. The L2C lock time for stations PRU1 and MAC2 in DOY 241 (left panel) shows gaps in the first $5 \mathrm{~min}$ of each hour. The gaps occur because the Septentrio PolaRxS-PRO receiver validates its outputs by checking the $\mathrm{C} / \mathrm{N} 0$ values with a certain threshold, which in case of the CIGALA project was found to be slight conservative causing such gaps (Sreeja et al. 2013). PALM and SJCU did not show such gaps on DOY 241. However, for SJCU several complete resets for L2C lock time were observed. Such resets seem to be related to the fact that GPS L2C signals are characterized by a lower transmission frequency with respect to $\mathrm{L} 1 \mathrm{C}$, as well as the lower signal transmission power (2.3 dB weaker than GPS L1C) (Sreeja et al. 2013). The lock times for L1C/A and L2C in DOY 329 show similar results for all stations, with many gaps for the same satellite, indicating that in conditions of strong scintillations the L1C/A and L2C observables are similarly affected.

Observing the time series in Figs. 2 and 3, it is possible to correlate the S4 indices with the lock time. Figure 4 shows the time series of S4 and lock time for L2C at station PRU1 for DOY 329. The receiver experienced loss of lock time regarding satellites PRN05, PRN12 and PRN31 as a function of increasing S4. However, in some cases a strong S4 did not result in loss of lock time, for instance see satellites PRN 25 and PRN 29. The same behavior of S4 indices and lock time was observed for tracked L1C/A. 
DOY 241
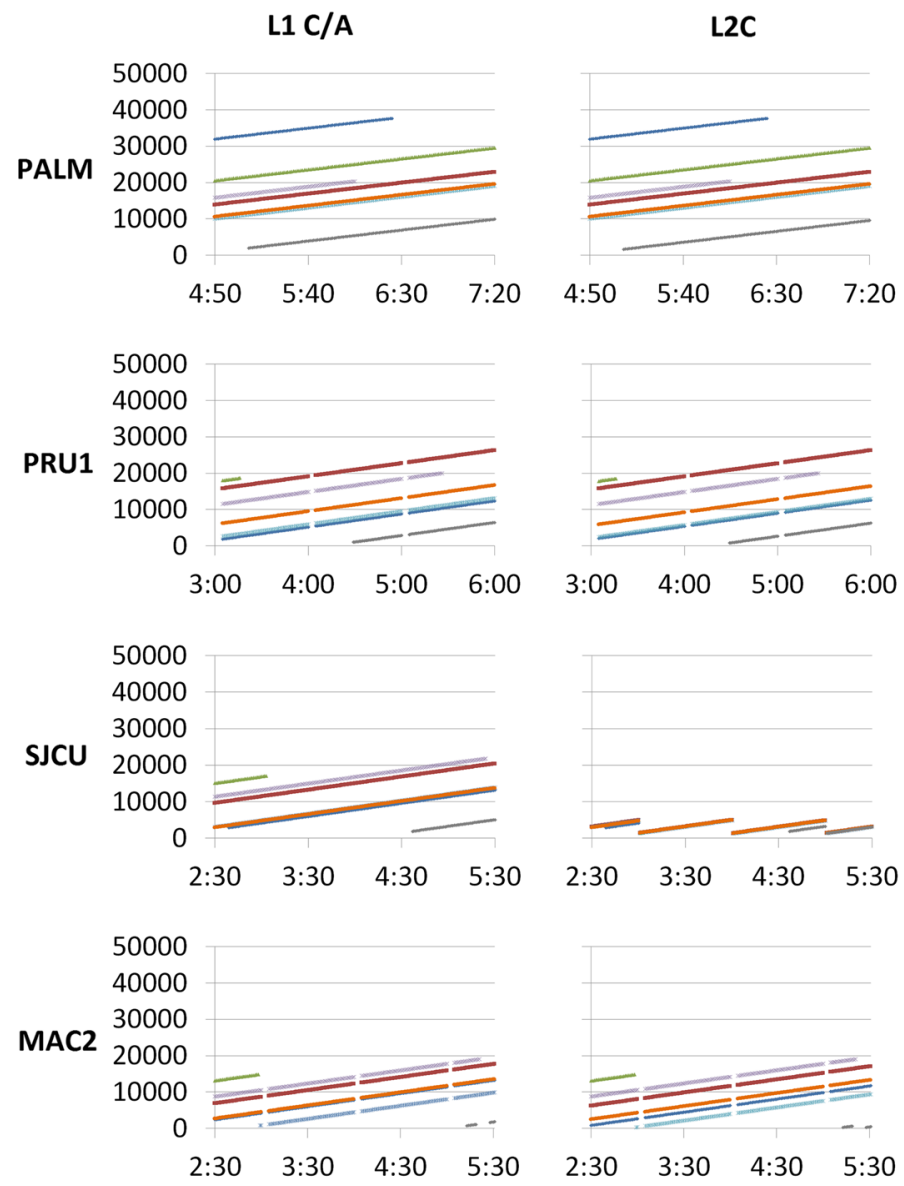

DOY 329

L1 C/A

L2C
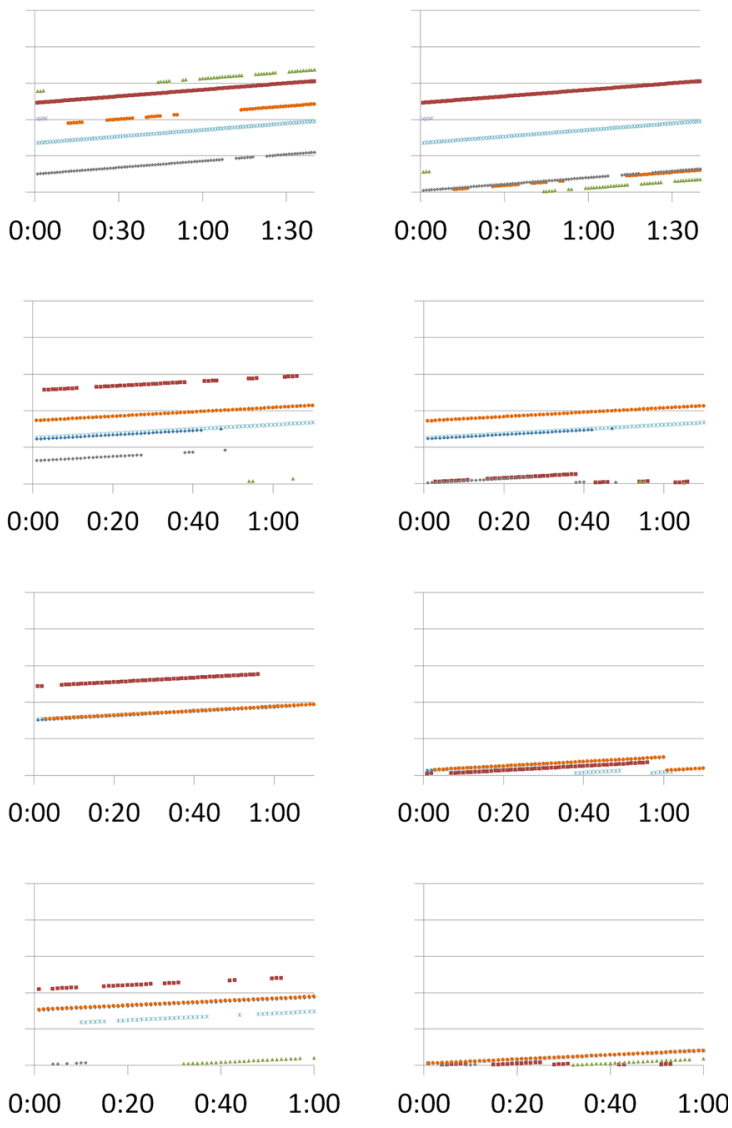

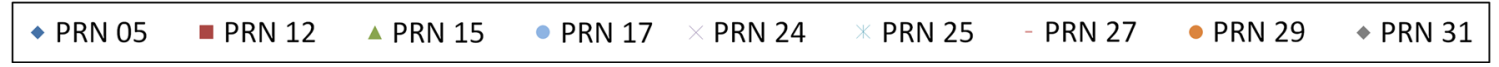

Fig. 3 Lock times (seconds) for L1C/A and L2C. Horizontal axis is UTC

Fig. 4 Lock time (seconds) and S4 for L2C at PRU1 for DOY 329. Horizontal axis is UTC
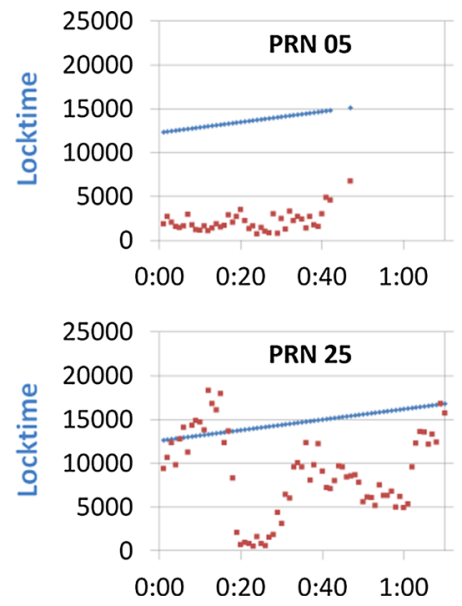

Even though the panels present S4 and lock time series only for PRU1, the same behavior was observed at the other stations for some of the satellites, indicating that sometimes the lock time can be correlated with $S 4$ index.

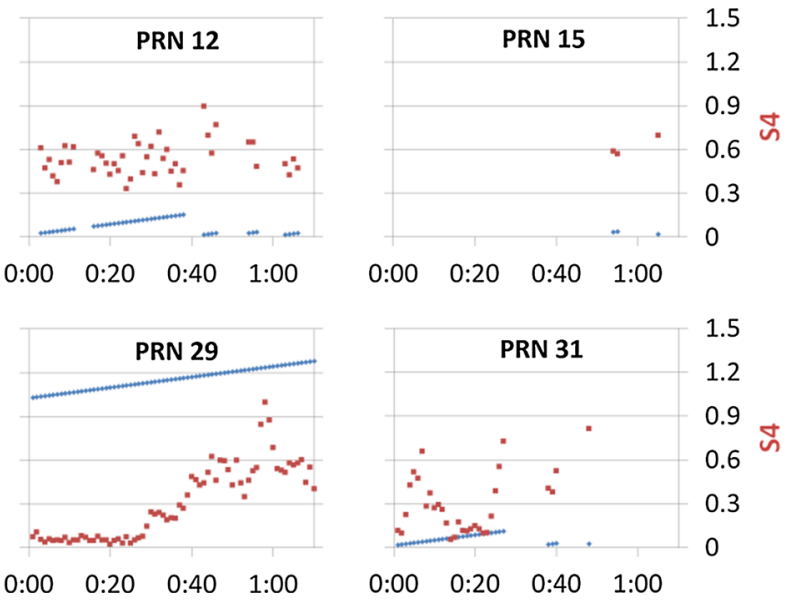

The multipath for L1 and L2 carriers was computed by using the TEQC (Translation Edition Quality and Control) program. The equations to compute multipath can be written as (Estey and Meertens 1999): 
$\mathrm{MP} 1=\mathrm{P}_{1}-\left(1+\frac{2}{\alpha-1}\right) \phi_{1}+\left(\frac{2}{\alpha-1}\right) \phi_{2}$

$\mathrm{MP} 2=\mathrm{P}_{2}-\left(\frac{2 \alpha}{\alpha-1}\right) \phi_{1}+\left(\frac{2 \alpha}{\alpha-1}\right) \phi_{2}$

where MP1 and MP2 are the multipath in L1 and L2. Further, $\mathrm{P}_{1}=\mathrm{P}_{1, \mathrm{C} / \mathrm{A}}$ and $\mathrm{P}_{2}=\mathrm{P}_{2, \mathrm{~L} 2 \mathrm{C} / \mathrm{P}(\mathrm{Y})}$ are the pseudoranges in $\mathrm{L} 1(\mathrm{C} / \mathrm{A})$ and $\mathrm{L} 2(\mathrm{~L} 2 \mathrm{C} / \mathrm{P}(\mathrm{Y})), \phi_{1}$ and $\phi_{2}$ are the carrier phases in L1 and L2, and $\alpha=\left(f_{1} / f_{2}\right)^{2}$.

The multipath values were computed based on (2) and (3). The following notation is used: MC1 (L1C/A), MP2 (L2P(Y)) and MC2 (L2C). Figure 5 shows the daily multipath RMS for the selected stations and DOY 241 and 329. The daily multipath RMS values for MC2 are in general smaller than those for MP2 for most of the satellites at all stations during DOY 241. The multipath errors for MC1 and MC2 show similar results, which is expected considering the characteristics of both signals (al-Fanek et al. 2007). However, for DOY 329, whose data are under moderate to strong ionospheric scintillation effects, the multipath RMS for MC2 did not follow the same behavior as in DOY 241 showing worse values compared to $\mathrm{MC1}$ and MP2 for some satellites, indicating that the MC2 multipath is strongly influenced during the occurrence of ionospheric scintillation.

\section{GPS data PPP processing}

The GPS data were processed using the in house RT_PPP software, which applies recursive least squares for static and kinematic PPP computations (Marques et al. 2014). The tropospheric errors can be corrected based on mathematical models only or corrected by the model and the residual part estimated as a random walk process. The firstorder ionospheric effects can be eliminated by applying the ionospheric-free linear combination or estimating the ionospheric effects. The software includes processing options for absolute phase center variation (PCV) for receiver and satellites, phase windup, relativity effects, ocean tide loading (OTL), earth body tides (EBT) and precise satellite orbits and clocks (Kouba and Héroux 2001; Seeber 2003; Leick et al. 2015; Kaplan and Hegarty 2006). The ambiguities are estimated as float solution. When a cycle slip is detected, the ambiguity parameter is reinitialized. Adjustment quality control is based on the detection, identification and adaptation (DIA) method as described by Teunissen (1998).

Despite the fact that the S4 and Phi60 indices have been analyzed considering intervals of $60 \mathrm{~s}$, the GPS data were processed at a rate of $15 \mathrm{~s}$. The data were processed in the PPP mode applying epoch-by-epoch solution for coordinates and receiver clock error, called kinematic PPP, even though the stations are static when collecting GPS data. The cutoff elevation mask was again $10^{\circ}$. Two different strategies were applied. In the first strategy, the ionospheric-free combination for code data was processed, combining $\mathrm{P}_{1, \mathrm{C} / \mathrm{A}}$ and $\mathrm{P}_{2, \mathrm{P}(\mathrm{Y})}$ pseudoranges and then combining $\mathrm{P}_{1, \mathrm{C} / \mathrm{A}}$ and $\mathrm{P}_{2, \mathrm{~L} 2 \mathrm{C}}$ pseudoranges. In the second strategy, the ionospheric-free code and phase data were processed combining $\mathrm{P}_{1, \mathrm{C} / \mathrm{A}}$ and $\mathrm{P}_{2, \mathrm{P}(\mathrm{Y})}$ pseudoranges and $\mathrm{L} 1$ and $\mathrm{L} 2$ carrier phases $\phi_{1}$ and $\phi_{2}$ and then $\mathrm{P}_{1, \mathrm{C} / \mathrm{A}}$ and $\mathrm{P}_{2, \mathrm{~L} 2 \mathrm{C}}$ pseudoranges and respective phases.

When using kinematic PPP in the RT_PPP software with code and phase data, the ambiguities are not estimated epoch by epoch, but the coordinates are. The phase ambiguity parameters are estimated in an accumulative solution in recursive least squares and treated as random constant

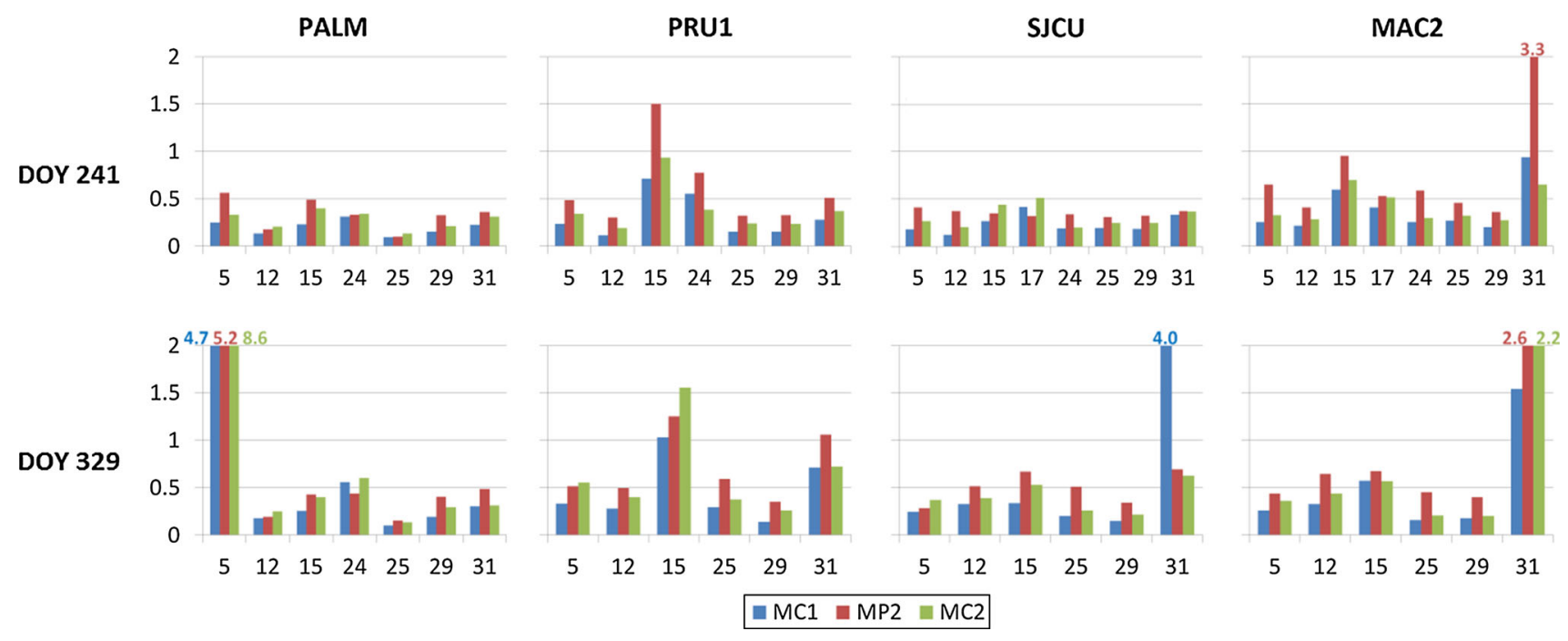

Fig. 5 Daily multipath RMS (in meters). Horizontal axis denotes satellites PRN 
process (Teunissen 2001). The tropospheric delay was corrected using the Hopfield model plus the global pressure and temperature (GPT) function (Boehm and Schuh 2004; Boehm et al. 2006). The PPP solution was carried out using final IGS orbits and clocks (30 s), absolute PCV, EBT, OTL, DCB, phase windup and relativity corrections. The stochastic model was applied based on the adopted precision of the observables and weighted by the inverse sine of the satellite elevation angle (Silva et al. 2010). The standard deviation of each undifferenced observable was adopted as $\sigma_{\mathrm{P} 1, \mathrm{C} / \mathrm{A}}=0.8 ; \sigma_{\mathrm{P} 2, \mathrm{~L} 2 \mathrm{C} \text { or } \mathrm{P}(\mathrm{Y})}=1.0 ; \sigma_{\phi 1}=0.008$ and $\sigma_{\phi 2}=0.010 \mathrm{~m}$, respectively, for $\mathrm{L} 1 \mathrm{C} / \mathrm{A}, \mathrm{L} 2 \mathrm{C}$ or $\mathrm{L} 2 \mathrm{P}(\mathrm{Y})$ pseudoranges and L1 and L2 carrier phases and then propagated for the ionospheric-free combination. No correlations among the observables were taken into account. The estimated coordinates were compared with ground truth coordinates, and the time series of 'errors' in the local geodetic system (DE, DN and DU-East, North and Up) were evaluated.

Figure 6 shows the coordinate errors estimated in the kinematic PPP processing using the ionospheric-free code functions. The figure shows that in general the time series errors show less dispersion when using $\mathrm{P}_{2, \mathrm{~L} 2 \mathrm{C}}$ compared to $\mathrm{P}_{2, \mathrm{P}(\mathrm{Y})}$ for both days. One can also see some peaks in the time series for stations SJCU and MAC2 on DOY 329 reaching values near $30 \mathrm{~m}$ with maximum peak of up to 150 meters. The occurrence of these peaks is related to maximum ionospheric scintillation intensity affecting some satellites, as can be seen in Fig. 2 .

It is also important to analyze the number of satellites tracking $\mathrm{P}_{2, \mathrm{~L} 2 \mathrm{C}}$ observable at each station. Figure 7 shows the satellite number for each station during the period involved in the PPP processing with ionosphere-free code observations. The figure shows that the number of satellites tracked at PALM ranged from 5 to 7 , whereas in general for the other stations the range is 5-6. Considering DOY 329 with moderate to strong ionospheric scintillation, some satellites experienced greater variability due to loss of lock time (Fig. 3) or outliers, which probably caused some peaks in the times series of coordinate errors mainly for stations SJCU and MAC2 as shown in Fig. 6.

Table 3 shows the daily RMS of the estimated coordinates and the improvements when using $\mathrm{P}_{2, \mathrm{~L} 2 \mathrm{C}}$ instead of $P_{2, P(Y)}$ with code data processed in the kinematic PPP. The daily RMS (code only) as shown in the table confirms that the results improve when using $\mathrm{P}_{2, \mathrm{~L} 2 \mathrm{C}}$ instead of $\mathrm{P}_{2, \mathrm{P}(\mathrm{Y})}$. The minimum and maximum improvement in RMS for DOY 241 was approximately 13 and $19 \%$, while for the DOY 329 the values are about 8 and $33 \%$.

Figure 8 shows the time series of errors in kinematic PPP using ionospheric-free code and phase functions. We see that for DOY 241 under weak ionospheric scintillation the DE, DN and DU are smaller when using $\mathrm{P}_{2, \mathrm{~L} 2 \mathrm{C}}$ rather than $\mathrm{P}_{2, \mathrm{P}(\mathrm{Y})}$. The same behavior does not apply to DOY 329 under moderate to strong ionospheric scintillation effects where the error time series presented reaches up to $17 \mathrm{~m}$, for instance, at PRU1 station, which can be related to cycle slips keeping in mind that in such cases the ambiguity parameters are reinitialized. In general, one can see that the estimated coordinates in kinematic PPP are more affected by code and phase measurements collected under moderate to strong ionospheric scintillation conditions.

The statistics for the kinematic PPP using ionosphericfree code and phase is given in Table 4. It is possible to verify that applying $\mathrm{P}_{2, \mathrm{~L} 2 \mathrm{C}}$ instead of $\mathrm{P}_{2, \mathrm{P}(\mathrm{Y})}$ in DOY 241 (weak ionospheric scintillation) the daily RMS improves, varying from about $0.5-44 \%$. However, for DOY 329 with moderate to strong ionospheric scintillation effects the application of $\mathrm{P}_{2, \mathrm{~L} 2 \mathrm{C}}$ provided no improvements in PPP. In contrast, the application of $\mathrm{P}_{2, \mathrm{P}(\mathrm{Y})}$ presented better daily $\mathrm{RMS}$ rather than $\mathrm{P}_{2, \mathrm{~L} 2 \mathrm{C}}$, which is unlike of all other results.

GPS data from other days during the year 2013 were also processed in kinematic PPP mode considering the same strategies as adopted above. These additional experiments were carried out in order to analyze more data intervals under different ionospheric scintillation conditions. Six days were chosen for stations PALM, PRU1 and SJCU. At MAC2, there were GPS data available only for 4 days during the chosen period. The 3D RMS and improvements in the PPP processing with ionospheric-free combination for code and code plus phase can be seen in Table 5.

Table 5 shows that the ionospheric-free code solutions improved in all cases using $\mathrm{P}_{2, \mathrm{~L} 2 \mathrm{C}}$ compared to using $\mathrm{P}_{2, \mathrm{P}(\mathrm{Y})}$, reaching maximum improvement of about $22 \%$ for SJCU in DOY 223. The ionospheric-free code and phase solutions using $\mathrm{P}_{2, \mathrm{~L} 2 \mathrm{C}}$ resulted in improvements for most of cases; however, only for DOY 223 at station PRU1 did the solution not improve for data under weak scintillation. In most of the other cases, no improvement in PPP processing with code and phase observations occurred for days with moderate ionospheric scintillation level.

\section{Conclusions}

We analyzed GPS L2C code observations for periods with weak, moderate and strong ionospheric scintillation effects in order to assess the L2C performance for positioning. Data from stations PALM, PRU1, SJCU and MAC2 of the CIGALA/CALIBRA network were analyzed in terms of ionospheric scintillation indices, lock time, multipath RMS and accuracy of kinematic PPP positioning. 
Fig. 6 Coordinate errors (in meters) for kinematic PPP using ionospheric-free code observations. Horizontal axis is UTC

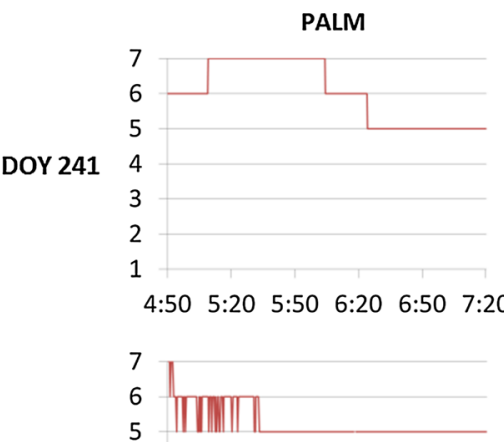

DOY 329

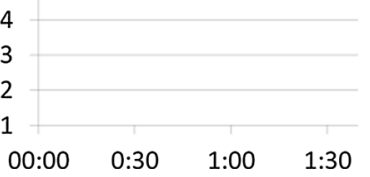

DOY 241

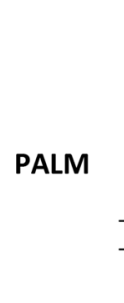

PRU1
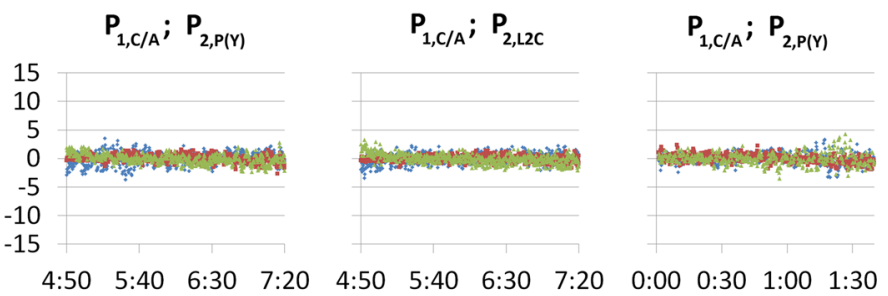

DOY 329

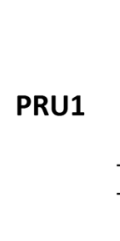

SJCU
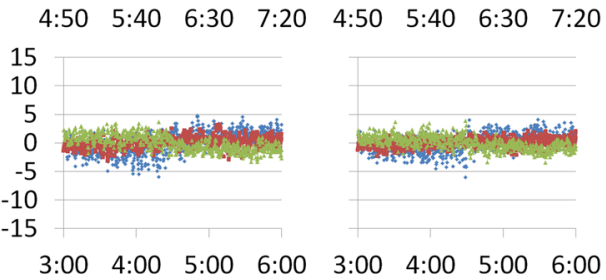

$\begin{array}{llll}0: 00 & 0: 30 & 1: 00 & 1: 30\end{array}$
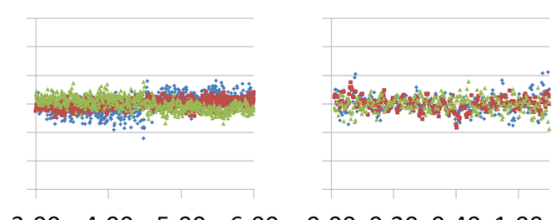

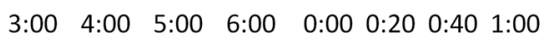
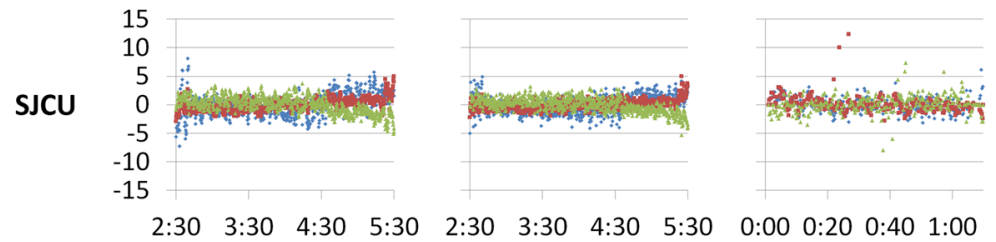

$0: 00 \quad 0: 20 \quad 0: 40 \quad 1: 00$
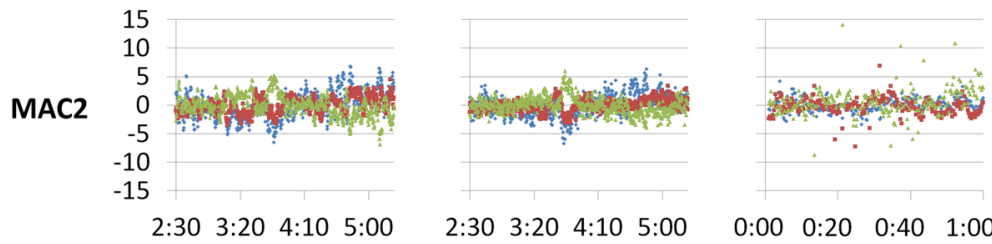

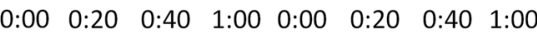

0:00 0:20 0:40 1:00

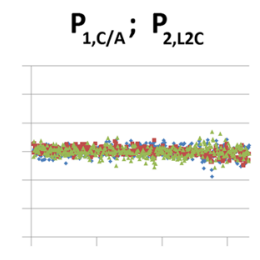

$\begin{array}{llll}0: 00 & 0: 30 & 1: 00 & 1: 30\end{array}$
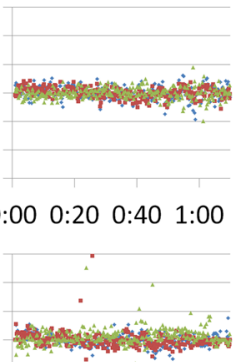

$$
\rightarrow \mathrm{DE} \quad \mathrm{DN} \triangle \mathrm{DU}
$$

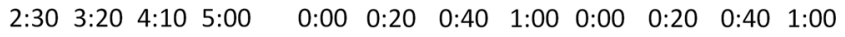

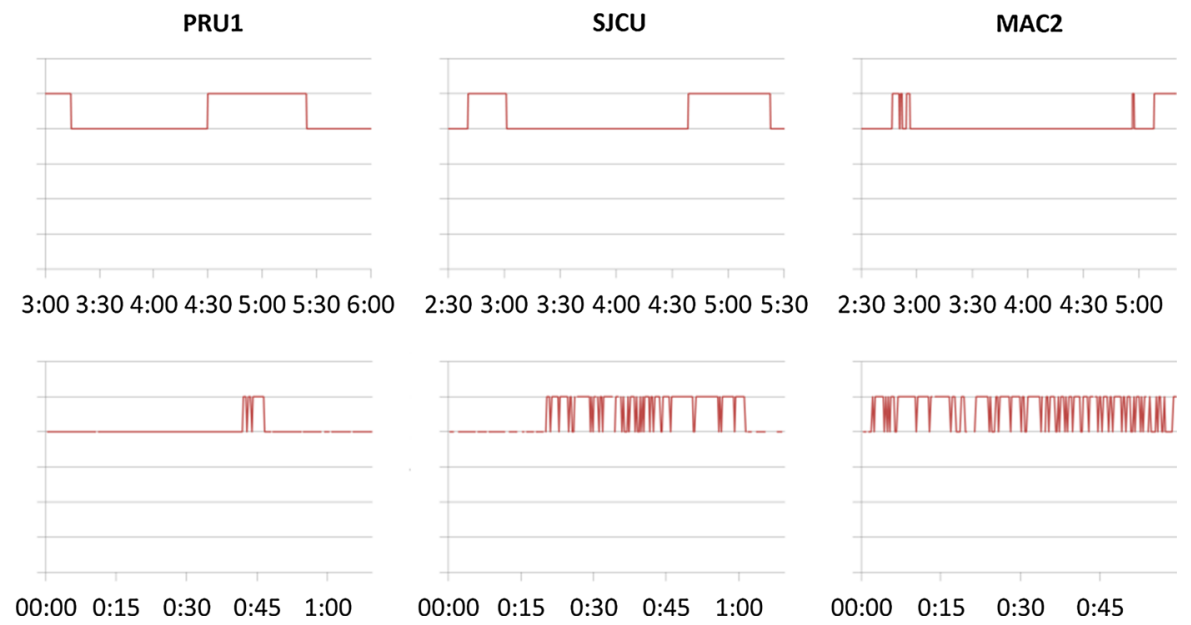

Fig. 7 Number of satellites with L2C tracked at stations PALM, PRU1, SJCU and MAC2. Horizontal axis is UTC

For DOY 241, 2013, which had weak ionospheric scintillation effects, the daily multipath RMS of L2C showed generally smaller values than MP2 for most of the satellites and all stations. The RMS multipath for the civil signals L1C/ A and L2C showed quite similar results. However, for DOY 329 , which had moderate to strong ionospheric scintillation effects, the RMS multipath for MC2 showed worse values compared to MC1 and MP2 for some satellites, indicating that MC2 multipath can be strongly influenced during occurrence of ionospheric scintillation.

Analyzing the times of continuous L2C lock, some stations presented several gaps that can be explained by the C/NO threshold applied in the Septentrio PolaRxS-PRO receiver. The lock time for L1C/A and L2C for DOY 329 showed similar results, with many gaps and resets for the same satellites, indicating that, in conditions of strong 
Table 3 Kinematic PPP daily RMS for $\mathrm{P}_{2, \mathrm{~L} 2 \mathrm{C}}$ and $\mathrm{P}_{2, \mathrm{P}(\mathrm{Y})}$ solutions using ionospheric-free code observables

\begin{tabular}{|c|c|c|c|c|c|c|}
\hline \multirow[t]{2}{*}{ Station } & \multicolumn{3}{|l|}{ DOY 241} & \multicolumn{3}{|l|}{ DOY 329} \\
\hline & $\begin{array}{l}\mathrm{RMS}(\mathrm{m}) \\
\mathrm{P}_{1, \mathrm{C} / \mathrm{A}} ; \mathrm{P}_{2, \mathrm{P}(\mathrm{Y})}\end{array}$ & $\begin{array}{l}\mathrm{RMS}(\mathrm{m}) \\
\mathrm{P}_{1, \mathrm{C} / \mathrm{A}} ; \mathrm{P}_{2, \mathrm{~L} 2 \mathrm{C}}\end{array}$ & Improvement (\%) & $\begin{array}{l}\mathrm{RMS}(\mathrm{m}) \\
\mathrm{P}_{1, \mathrm{C} / \mathrm{A}} ; \mathrm{P}_{2, \mathrm{P}(\mathrm{Y})}\end{array}$ & $\begin{array}{l}\mathrm{RMS}(\mathrm{m}) \\
\mathrm{P}_{1, \mathrm{C} / \mathrm{A}} ; \mathrm{P}_{2, \mathrm{~L} 2 \mathrm{C}}\end{array}$ & Improvement (\%) \\
\hline PALM & 1.55 & 1.36 & 12.6 & 1.60 & 1.47 & 8.3 \\
\hline PRU1 & 2.48 & 2.05 & 17.1 & 2.28 & 1.83 & 19.8 \\
\hline SJCU & 2.53 & 2.06 & 18.7 & 3.65 & 3.29 & 9.8 \\
\hline MAC2 & 3.09 & 2.50 & 19.1 & 4.56 & 3.06 & 32.9 \\
\hline
\end{tabular}

Fig. 8 Coordinate errors (meters) in the PPP processing using ionospheric-free code and phase observables. Horizontal axis is UTC

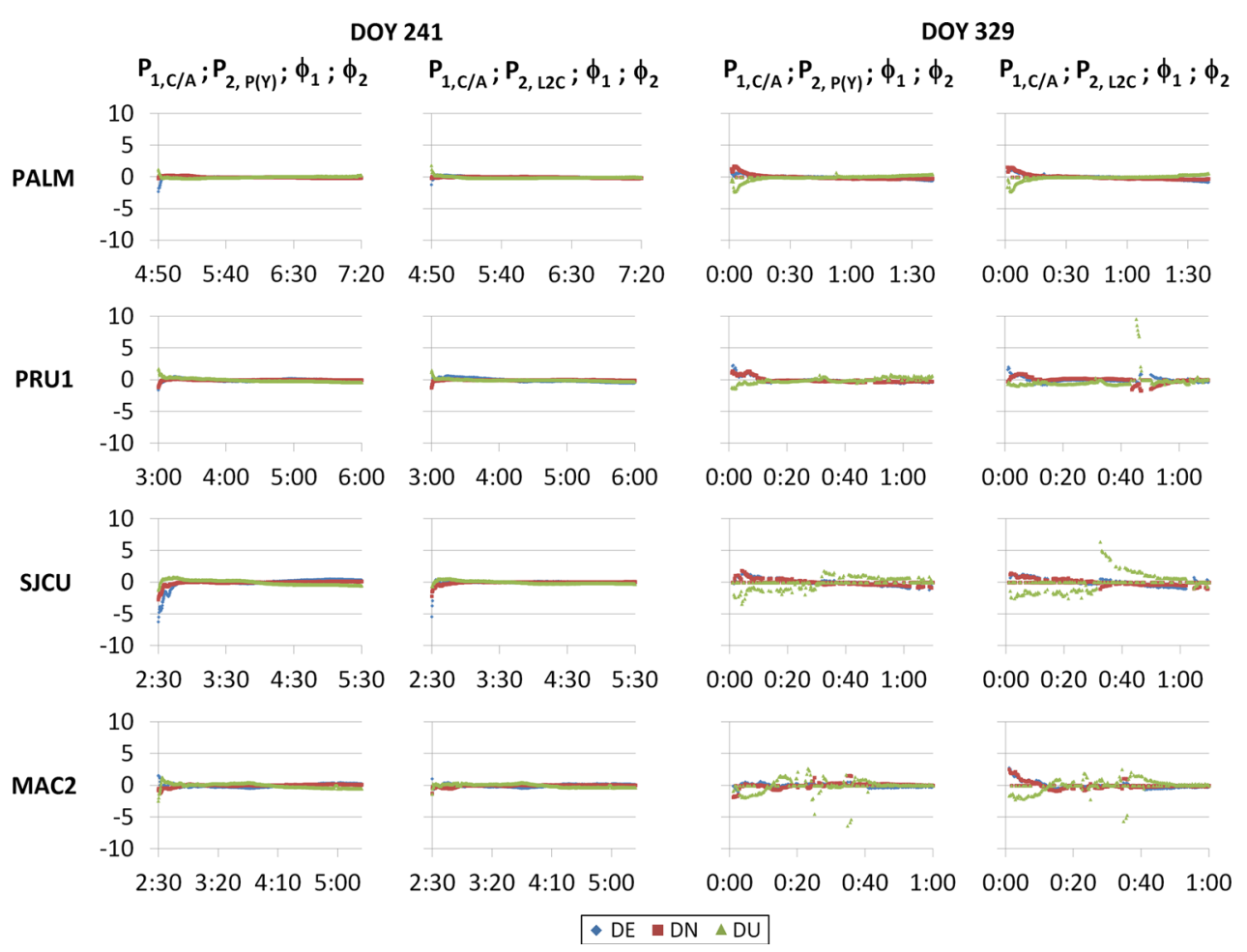

Table 4 Daily RMS of kinematic PPP and improvements using ionospheric-free code and phase observations

\begin{tabular}{|c|c|c|c|c|c|c|}
\hline \multirow[t]{2}{*}{ Station } & \multicolumn{3}{|l|}{ DOY 241} & \multicolumn{3}{|l|}{ DOY 329} \\
\hline & $\begin{array}{l}\text { RMS }(\mathrm{m}) \\
\mathrm{P}_{1, \mathrm{C} / \mathrm{A}} ; \mathrm{P}_{2, \mathrm{P}(\mathrm{Y})} \\
\phi_{1} \text { and } \phi_{2}\end{array}$ & $\begin{array}{l}\mathrm{RMS}(\mathrm{m}) \\
\mathrm{P}_{1, \mathrm{C} / \mathrm{A}} ; \mathrm{P}_{2, \mathrm{~L} 2 \mathrm{C}} \\
\phi_{1} \text { and } \phi_{2}\end{array}$ & Improvement (\%) & $\begin{array}{l}\text { RMS }(\mathrm{m}) \\
\mathrm{P}_{1, \mathrm{C} / \mathrm{A}} ; \mathrm{P}_{2, \mathrm{P}(\mathrm{Y})} \\
\phi_{1} \text { and } \phi_{2}\end{array}$ & $\begin{array}{l}\mathrm{RMS}(\mathrm{m}) \\
\mathrm{P}_{1, \mathrm{C} / \mathrm{A}} ; \mathrm{P}_{2, \mathrm{~L} 2 \mathrm{C}} ; \\
\phi_{1} \text { and } \phi_{2}\end{array}$ & Improvement (\%) \\
\hline PALM & 0.43 & 0.43 & 0.5 & 0.79 & 0.84 & -6.2 \\
\hline PRU1 & 0.58 & 0.51 & 10.7 & 0.90 & 1.64 & -81.0 \\
\hline SJCU & 1.05 & 0.59 & 43.7 & 1.33 & 1.60 & -20.1 \\
\hline MAC2 & 0.70 & 0.57 & 18.6 & 1.27 & 1.40 & -10.3 \\
\hline
\end{tabular}

scintillations, the lock time of L1C/A and L2C observables is similarly affected. Loss of lock occurred more frequently for the day with moderate to strong ionospheric scintillation, showing a noticeable correlation with the number of satellites available for PPP processing. The variability in number of visible satellites, mainly for stations SJCU and MAC2, degraded the estimation of coordinates in PPP processing.

The experiments in the coordinates domain considering kinematic PPP for static stations were carried out using ionospheric-free combinations for codes $\left(\mathrm{P}_{1, \mathrm{C} / \mathrm{A}}\right.$ and 
Table 5 Daily RMS of kinematic PPP for additional experiments

\begin{tabular}{|c|c|c|c|c|c|c|c|c|}
\hline Station & DOY & $\begin{array}{l}\text { 3D RMS (m) } \\
\mathrm{P}_{1, \mathrm{C} / \mathrm{A}} ; \mathrm{P}_{2, \mathrm{P}(\mathrm{Y})}\end{array}$ & $\begin{array}{l}\text { 3D RMS (m) } \\
\mathrm{P}_{1, \mathrm{C} / \mathrm{A}} ; \mathrm{P}_{2, \mathrm{~L} 2 \mathrm{C}}\end{array}$ & $\begin{array}{l}\text { Improvement } \\
(\%)\end{array}$ & $\begin{array}{l}3 \mathrm{D} \text { RMS (m) } \\
\mathrm{P}_{1, \mathrm{C} / \mathrm{A}} ; \mathrm{P}_{2, \mathrm{P}(\mathrm{Y})} \\
\phi_{1} ; \phi_{2}\end{array}$ & $\begin{array}{l}3 \mathrm{D} \text { RMS (m) } \\
\mathrm{P}_{1, \mathrm{C} / \mathrm{A}} ; \mathrm{P}_{2, \mathrm{~L} 2 \mathrm{C}} \\
\phi_{1} ; \phi_{2}\end{array}$ & $\begin{array}{l}\text { Improvement } \\
(\%)\end{array}$ & $\begin{array}{l}\text { Scintillation } \\
\text { level }\end{array}$ \\
\hline \multirow[t]{6}{*}{ PALM } & 217 & 1.44 & 1.35 & 6.0 & 0.67 & 0.60 & 10.5 & Weak \\
\hline & 223 & 1.44 & 1.37 & 4.9 & 0.76 & 0.63 & 17.3 & Weak \\
\hline & 229 & 1.50 & 1.37 & 9.0 & 0.75 & 0.58 & 23.1 & Weak \\
\hline & 302 & 1.57 & 1.53 & 2.8 & 0.55 & 0.57 & -4.0 & Moderate \\
\hline & 318 & 1.78 & 1.42 & 20.4 & 0.95 & 0.85 & 9.6 & Moderate \\
\hline & 338 & 1.84 & 1.64 & 10.6 & 0.65 & 0.67 & -2.9 & Moderate \\
\hline \multirow[t]{6}{*}{ PRU1 } & 217 & 2.55 & 2.42 & 5.1 & 1.16 & 1.02 & 12.0 & Weak \\
\hline & 223 & 2.61 & 2.39 & 8.4 & 1.11 & 1.35 & -22.2 & Weak \\
\hline & 229 & 2.51 & 2.07 & 17.6 & 0.81 & 0.58 & 28.4 & Weak \\
\hline & 302 & 2.36 & 2.14 & 9.1 & 0.76 & 0.66 & 12.8 & Moderate \\
\hline & 318 & 2.10 & 1.75 & 16.6 & 1.01 & 0.85 & 16.3 & Moderate \\
\hline & 338 & 2.44 & 2.18 & 10.8 & 1.58 & 1.67 & -5.7 & Moderate \\
\hline \multirow[t]{6}{*}{ SJCU } & 217 & 2.61 & 2.18 & 16.5 & 1.21 & 0.75 & 38.2 & Weak \\
\hline & 223 & 2.90 & 2.27 & 21.7 & 1.70 & 1.00 & 41.3 & Weak \\
\hline & 229 & 2.42 & 2.18 & 9.6 & 0.84 & 0.65 & 22.8 & Weak \\
\hline & 302 & 2.60 & 2.15 & 17.2 & 1.24 & 1.10 & 11.2 & Moderate \\
\hline & 318 & 2.07 & 1.79 & 13.4 & 0.95 & 0.91 & 3.7 & Moderate \\
\hline & 338 & 2.00 & 1.77 & 11.5 & 1.22 & 1.23 & -1.5 & Moderate \\
\hline \multirow[t]{4}{*}{ MAC2 } & 229 & 2.55 & 2.47 & 3.2 & 0.85 & 0.51 & 40.7 & Weak \\
\hline & 302 & 2.69 & 2.18 & 19.0 & 1.24 & 0.86 & 30.9 & Weak \\
\hline & 318 & 2.79 & 2.69 & 3.8 & 1.88 & 1.85 & 1.4 & Moderate \\
\hline & 338 & 3.39 & 2.41 & 28.7 & 1.27 & 0.53 & 58.6 & Weak \\
\hline
\end{tabular}

$\mathrm{P}_{2, \mathrm{P}(\mathrm{Y})} ; \mathrm{P}_{1, \mathrm{C} / \mathrm{A}}$ and $\left.\mathrm{P}_{2, \mathrm{~L} 2 \mathrm{C}}\right)$, followed by combining codes and phases $\left(\mathrm{P}_{1, \mathrm{C} / \mathrm{A}}, \mathrm{P}_{2, \mathrm{P}(\mathrm{Y})}, \phi_{1}, \phi_{2} ; \mathrm{P}_{1, \mathrm{C} / \mathrm{A}}, \mathrm{P}_{2, \mathrm{~L} 2 \mathrm{C}}, \phi_{1}, \phi_{2}\right)$. The daily RMS of coordinates estimated using only codes showed improvements for weak and strong scintillation effects, reaching maximum of about $33 \%$ when using $\mathrm{P}_{2, \mathrm{~L} 2 \mathrm{C}}$ instead of $\mathrm{P}_{2, \mathrm{P}(\mathrm{Y})}$ in DOY 329. PPP using code and phase measurements presented improvements at times with weak ionospheric scintillation (DOY 241) reaching the maximum of about $44 \%$ when $\mathrm{P}_{2, \mathrm{~L} 2 \mathrm{C}}$ was applied. However, under strong ionospheric scintillation effects (DOY 329) the daily coordinates RMS values reversed, i.e., $\mathrm{P}_{2, \mathrm{P}(\mathrm{Y})}$ provided better solutions than L2C.

The analysis was expanded by an additional 6 days of GPS data for stations that experienced weak and moderate ionospheric scintillation effects. In all cases, PPP positioning with code data improved the results up to about $22 \%$ when using $\mathrm{P}_{2, \mathrm{~L} 2 \mathrm{C}}$ instead of $\mathrm{P}_{2, \mathrm{P}(\mathrm{Y})}$. However, in some cases with code and phase data collected under moderate scintillation effects the PPP daily RMS applying $\mathrm{P}_{2, \mathrm{P}(\mathrm{Y})}$ provided better values than $\mathrm{P}_{2, \mathrm{~L} 2 \mathrm{C}}$.

The experiments carried out in this research lead the conclusion that under weak ionospheric scintillation the
L2C performance is considerable better in positioning when using only codes and also when combining code and carrier phases. However, the daily RMS of the estimated coordinates was degraded in most of cases when using code and carrier phases under moderate to strong ionospheric scintillation effects, showing that under such conditions the L2C signal can be strongly influenced.

Acknowledgments The authors would like to thank FAPESP (Foundation for Research Support of São Paulo) for the financial support for the development of the project under contract 2011/01196-0 and 2006/04008-2, and also the support of the Brazilian $\mathrm{CNPq}$ (National Council of Research and Developing) of the University under contract 475775/2013-9. Thanks to Post Graduate Program in Cartography Science of FCT/UNESP (Sao Paulo State University) for providing structure and support. Thanks to the CIGALA/CALIBRA project carried out under the Seventh Framework Program (FP7) funded by European GNSS Agency (GSA).

\section{References}

Al-Fanek O, Skone S, Lachapelle G (2007) Evaluation of L2C observations and limitations. In: Proceedings of the ION GNSS 2007, Institute of Navigation, Fort Worth, pp 2510-2518 
Aquino M, Monico JFG, Dodson AH, Marques HA, De Franceschi G, Alfonsi L, Romano V, Andreotti M (2009) Improving the GNSS positioning stochastic model in the presence of Ionospheric scintillation. J Geod 83:953-966. doi:10.1007/s00190-009-0313-6

Boehm J, Schuh H (2004) Vienna mapping functions in VLBI analyses. Geophys Res Lett 31:L01603. doi:10.1029/ 2003GL018984

Boehm J, Niell A, Tregoning P, Schuh H (2006) Global mapping function (GMF): a new empirical mapping function based on numerical weather model data. Geophys Res Lett 33:L07304. doi:10.1029/2005GL025546

Conker RS, El-Arini B, Hegarty CJ, Hsiao T (2002) Modeling the effects of ionospheric scintillation on GPS/satellite-based augmentation system availability. Radio Sci 37:1-23. doi:10.1029/ 2000RS002604

Davies K (1990) Ionospheric radio. Short Run Press LTd, England

Estey LH, Meertens CM (1999) TEQC: the multi-purpose toolkit for GPS/ GLONASS data. GPS Solut 3:42-49. doi:10.1007/PL00012778

OS-SIS-ICD (2010) European GNSS (Galileo) OpenService. Signal in space interface control document. http://ec.europa.eu/enter prise/policies/satnav/galileo/files/galileo-os-sis-icd-issue1-revisio n1_en.pdf. Accessed 2 May 2015

Hinks JC, Humphreys TE, O'Hanlon B, Psiaki ML, Kintner Jr PM (2008) Evaluating GPS receiver robustness to ionospheric scintillation. In: Proceedings of the ION GNSS 2008, Institute of Navigation, Savannah, pp 309-320

IS-GPS-200G (2012) Global positioning system directorate systems engineering and integration: interface specification IS-GPS-200. http://www.gps.gov/technical/icwg/IS-GPS-200G.pdf. Accessed 16 Aug 2014

Kaplan E, Hegarty C (2006) Understanding GPS: principles and applications, 2nd edn. Artech House, Norwood

Kouba J, Héroux P (2001) Precise point positioning using IGS orbit and clock products. GPS Solut 5:12-28. doi:10.1007/ PL00012883

Leick A, Rapoport L, Tatarnikov D (2015) GPS satellite surveying, 4th edn. Wiley, New York

Maini AK, Agrawal V (2007) Satellite technology: principles and applications. Wiley, Hoboken

Marques H, Monico J, Aquino M, Melo W (2014) Satellite clock corrections estimation to accomplish real time PPP: experiments for Brazilian real time network 2014 proceedings of the EGU General Assembly 16EGU2014-13552

Seeber G (2003) Satellite geodesy: foundations, methods, and applications, 2nd edn. Walter de Gruyter, Berlin

Silva HA, Camargo PO, Monico JFG, Aquino M, Marques HA, De Franceschi G, Dodson A (2010) Stochastic modelling considering ionospheric scintillation effects on GNSS relative and point positioning. Adv Space Res 45:1113-1121. doi:10.1016/j.asr. 2009.10.009

Skone S, Knudsen K, de Jong M (2001) Limitations in GPS receiver tracking performance under ionospheric scintillation conditions. Phys Chem Earth Part A 26:613-621. doi:10.1016/S14641895(01)00110-7

Sreeja V, Aquino M, Elmas Z, Forte B (2013) Correlation analysis between ionospheric scintillation levels and receiver tracking performance. Space Weather 10:S06005. doi:10.1029/ 2012SW000769

Teunissen PJG (1998) Quality control and GPS. In: Teunissen PJG, Kleusberg A (eds) A GPS for geodesy, 2nd edn. Springer, Berlin, pp 271-318

Teunissen PJG (2001) Dynamic data processing: recursive leastsquares. Delft University Press, Delft

Tiwari R, Skone S, Tiwari S, Strangeways HJ (2011) WBMod Assisted PLL GPS software receiver for mitigating scintillation affect in high latitude region. In: General assembly and scientific symposium, XXXth URSI, pp 1-4

Van Dierendonck AJ (2001) Measuring ionospheric scintillation effects from GPS signals. In: Proceedings of the 57th annual meeting. Institute of Navigation, Albuquerque, pp 391-396

Wang D, O'Keefe K (2010) Benefit of partial L2C availability to estimate ionospheric delay for dual-frequency GPS ambiguity resolution. In: Proceedings of the position location and navigation symposium (PLANS) IEEE/ION 06/2010

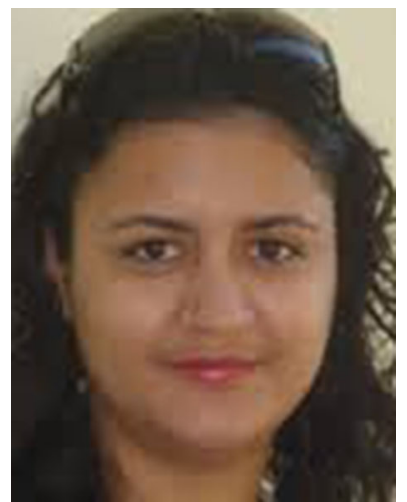

Heloísa Alves Silva Marques received her B.Sc. degree in Cartographic Engineering in 2006, M.Sc. in Cartographic Science in 2009 and Ph.D. in Cartographic Science in 2013 at Sao Paulo State University (UNESP) at Presidente Prudente in Brazil. Since 2014, she is an Adjunct Professor at the Section of Cartographic Engineering, Military Engineering Institute (IME) at Rio de Janeiro. Her current research is in Geodesy including GNSS Positioning, Atmospheric Sciences and GNSS Coordinate Time Series Analysis.

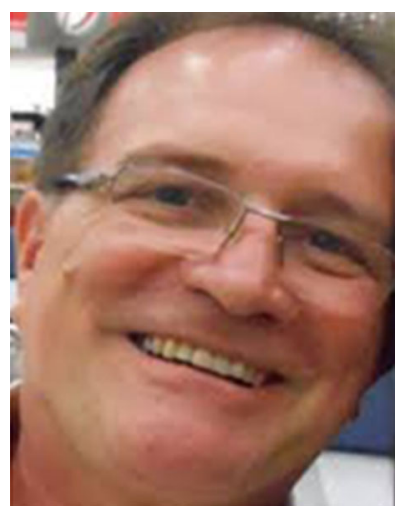

João Francisco Galera Monico received his B.Sc. degree in Cartographic Engineering in 1982, M.Sc. in Geodetic Science in 1988 and Ph.D. in Space Geodesy in 1995. From 2005 to 2013, he was an Adjunct Professor at the Department of Cartography, Sao Paulo State University (UNESP) at Presidente Prudente in Brazil, where he was lecturing and researching topics related to GNSS, especially those related to Geodesy, Surveying, and Atmospheric Sciences. Now, he is a researcher also with UNESP at the same Department.

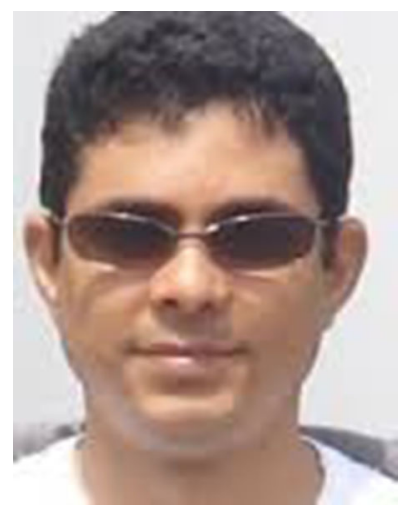

Haroldo Antonio Marques received his B.Sc. degree in Cartographic Engineering in 2005, M.Sc. in Cartographic Science in 2008 and Ph.D. in Cartographic Science in 2012 at Sao Paulo State University (UNESP), Presidente Prudente in Brazil. Since 2011, he is an Adjunct Professor at the Department of Cartographic Engineering, Federal University of Pernambuco (UFPE) at Recife in Brazil, where he is lecturing and researching topics related to Geodesy and Adjustment, especially those related to GNSS, Surveying, and Atmospheric Sciences. 